\title{
First OR Temperature
}

National Cancer Institute

\section{Source}

National Cancer Institute. First OR Temperature. NCI Thesaurus. Code C159282.

The first body temperature recorded in the operating room for the participant. 